RU Применение цифровых технологий при обучении лексике иностранного языка в высшей школе

Колесниченко А. Н.

\begin{abstract}
Аннотация. Цель исследования - проанализировать возможности применения цифровых технологий при обучении лексике иностранного языка в высшей школе. В статье рассматривается понятие «цифровые технологии», актуальность использования цифровых технологий, возросшая в период цифровизации и пандемии коронавируса и связанная с переходом на дистанционный формат обучения. Научная новизна исследования состоит в том, что представлены способы использования цифровых ресурсов при обучении лексике иностранного языка в вузе. Полученные результаты комплексного анализа цифровых технологий доказывают эффективность использования электронных ресурсов в преподавании иностранных языков в высшей школе для формирования компетенций личности.
\end{abstract}

\title{
EN Using Digital Technologies When Teaching Foreign Language Vocabulary to Higher School Students
}

\author{
Kolesnichenko A. N.
}

\begin{abstract}
The paper reveals a potential of digital technologies when teaching foreign language vocabulary to higher school students. The article covers the following issues: the notion “digital technologies", growing relevance of digital technologies under the conditions of transition to distant learning forced by coronavirus pandemic. Scientific originality of the study lies in the fact that the author describes methodology of using digital technologies when teaching foreign language vocabulary to higher school students. The analysis indicates that electronic resources can be efficiently used to form higher school students' foreign-language competence.
\end{abstract}

\section{Введение}

Актуальность исследования обусловлена новыми условиями обучения, с которыми столкнулись школы и вузы в связи с пандемией коронавируса и необходимостью перехода на дистанционное обучение. Переход на дистанционный формат обучения заставил участников образовательного процесса воспользоваться цифровыми технологиями на занятиях по всем изучаемым дисциплинам. С одной стороны, такой формат обучения имел определенные недостатки, связанные с техническим обеспечением наших регионов - отсутствием высокоскоростного интернета, с проблемами организации образовательного процесса в виртуальном пространстве и т.п. С другой стороны, удаленная форма обучения дала возможность преподавателям чаще обычного использовать на своих занятиях современные цифровые технологии - различные онлайн-курсы, электронные учебники, учебные видео и т.д.

Интерес изучения цифровых технологий в преподавании иностранных языков обусловлен также противоречивым освещением данного вопроса в научной литературе. В педагогической науке до сих пор остается нерешенным вопрос о выборе наиболее эффективного дидактического подхода, лежащего в основе разработки методики цифрового обучения. Ученые Е. С. Полат [6], П. Я. Гальперин [2] занимались вопросами изучения цифрового, сетевого, дистанционного обучения иностранным языкам с применением компьютерных технологий на основе взаимосвязи двух подходов - деятельностного и компетентностного, предполагающих получение не просто информации, знаний, а формирование компетенций посредством цифровых технологий. Актуальность работы вызвана необходимостью найти подтверждение концепции «формирование компетенций как результат применения цифровых технологий в процессе преподавания иностранных языков в вузе», а также представить способы обучения лексике иностранного языка с использованием разнообразных цифровых ресурсов.

Научная статья (original research article) । https://doi.org/10.30853/ped210023

(๔ 2021 Авторы. ООО Издательство «Грамота» (๔ 2021 The Authors. GRAMOTA Publishers). Открытый доступ предоставляется на условиях лицензии СС ВY 4.0 (open access article under the CС BY 4.0 license): https://creativecommons.org/licenses/by/4.0/ 
Для достижения поставленной цели необходимо решить следующие задачи:

- раскрыть понятие «цифровые технологии» и определить функции информационно-коммуникационных технологий в образовательном процессе;

- описать и проанализировать цифровые ресурсы, используемые при обучении лексике иностранного языка в высшей школе и направленные на формирование необходимых компетенций обучающихся.

В качестве основных методов исследования используются следующие: метод контент-анализа, в результате которого был сделан анализ доступных интернет-ресурсов с целью получения необходимой информации - оценки эффективности их использования при обучении лексике иностранного языка; систематизация и классификация; методы эмпирического исследования - описание и сравнение - позволили проанализировать цифровые технологии, выделить их общие и отличительные признаки.

Теоретической базой исследования стали научные работы ученых: Е. С. Полат [6], Т. Е. Исаевой [3], С. М. Кащук [4], И. В. Роберт [8], посвященные методологическим вопросам применения цифровых технологий в процессе обучения иностранным языкам в вузе.

Практическая значимость исследования заключается в том, что изученный комплекс цифровых ресурсов может найти практическое применение в педагогической деятельности преподавателей иностранных языков для усовершенствования образовательного процесса в высшей школе.

\section{Понятие «цифровые технологии» и функции информационно-коммуникационных технологий в образовательном процессе}

В научной литературе употребляется несколько синонимичных терминов: «информационно-коммуникационные технологии», «информационные технологии», «компьютерные технологии», «цифровые технологии» $[1 ; 6 ; 9 ; 10]$. Такое разнообразие названий объясняется тем, что все они указывают на применение информационных ресурсов - документов, находящихся в информационных системах, то есть архивах, библиотеках, фондах, базах данных и т.п. Следовательно, эти понятия, на наш взгляд, взаимозаменяемы.

Помимо разнообразия терминов в педагогических исследованиях можно встретить и множество разноплановых определений понятия «цифровые технологии». Так, Л. А. Артюшина, Т. В. Спирина, Е. А. Троицкая, давая формулировку информационно-коммуникационным образовательным технологиям, подчеркивают важность достижения педагогических целей, поэтому информационные потоки должны способствовать взаимосвязи всех сторон образовательного процесса: преподавателей, обучающихся, родителей, администрации и общественности [1, с. 73; 10, с. 27]. Е. А. Троицкая так раскрывает понятие «информационные образовательные технологии»: «...все технологии в сфере образования, использующие специальные технические информационные средства (компьютер, аудио, кино, видео) для достижения педагогических целей» [10, с. 27]. Другие исследователи (А. В. Польщиков, А. М. Ямалетдинова и А. С. Медведева) к цифровым технологиям относят совокупность методов, включающих вычислительную технику, средства телекоммуникации, программно-технические средства, которые выполняют функции сбора, обработки, хранения, отображения, предоставления данных, представляющих интерес для пользователей [7, с. 33; 11, с. 1134].

Учитывая разносторонние определения понятия «цифровые технологии», наиболее полной и системной следует считать формулировку, данную Т. Е. Исаевой: «Информационно-коммуникационные технологии в обучении иностранным языкам - это совокупность современных педагогических технологий, основанных на активном использовании в процессе дистанционного, смешанного, группового, индивидуализированного образования компьютерных и сетевых средств обучения, направленных на создание условий, моделирующих реальное иноязычное взаимодействие для развития познавательных, учебных и творческих способностей обучающихся в ходе разного рода коммуникаций» [3, с. 113]. В этом определении показана не только роль цифровых технологий в познавательной активности обучающихся, но и обозначена их полифункциональность, позволяющая использовать современные технологии в разных видах обучения.

И. В. Роберт отмечает, что «в условиях информатизации образования меняется парадигма педагогической науки, изменяется структура и содержание образования. Новые методы обучения, основанные на активных, самостоятельных формах приобретения знаний и работе с информацией, вытесняют демонстрационные и иллюстративно-объяснительные методы, широко используемые традиционной методикой обучения, ориентированной в основном на коллективное восприятие информации. Параллельно этому идет процесс использования программных средств и систем учебного назначения (пакетов программных средств учебного назначения) для поддержки традиционных методов обучения. Программным средствам (системам), используемым в учебных целях, передаются в какой-то мере обучающие функции и, следовательно, каждая программа должна строиться сообразно дидактическим принципам обучения, определяющим дидактические требования к ППС» [8, с. 20]. Соответственно, цифровые технологии, несмотря на современный способ взаимодействия преподавателя и студентов с применением технических средств, направлены на решение традиционных педагогических задач, так как в процессе обучения иностранным языкам выполняют такие основные функции, как:

- обучающая, которая заключается в представлении нового материала, получении необходимых речевых умений и навыков, контроле их использования;

- воспитывающая, направленная на формирование личностных качеств, ценностей, взглядов, универсальных и профессиональных компетенций студентов, подразумевающих изучение культуры страны изучаемого языка, правил речевого и поведенческого этикета; 
- развивающая, способствующая разностороннему развитию личности, улучшению мышления и умственных способностей человека с применением заданий творческого характера, решением коммуникативных задач разной направленности, выполнением проектной деятельности и т.п.;

- мотивирующая, которая состоит в привлечении обучающихся к изучаемой дисциплине - иностранный язык благодаря использованию на занятиях наглядности, полного «погружения» в иноязычную среду, созданную с применением цифровых технологий;

- познавательная, заключающаяся в формировании системы научных взглядов и умений применять их на практике, чему способствуют разные коммуникативные контакты обучающихся [9, с. 27].

Таким образом, цифровые технологии решают основные задачи педагогики и способствуют формированию у обучающихся всех необходимых общекультурных и профессиональных компетенций личности, что содействует приобретению личного опыта, применению полученных знаний, умений и навыков на практике.

\section{Преимущества использования цифровых ресурсов как средств обучения лексике иностранного языка в высшей школе}

Преимущество использования цифровых технологий отмечает Е. С. Полат в своих трудах: «Отличаясь высокой степенью интерактивности, компьютерные телекоммуникации способствуют созданию уникальной учебно-познавательной среды, т.е. среды, используемой для решения различных дидактических задач (например, познавательных, информационных, культурологических и др.). Главной особенностью данной среды является то, что она пригодна как для массового, так и для сугубо индивидуального обучения и самообучения» [6, с. 153]. Однако вопрос о классификации цифровых технологий также вызывает много противоречивых мнений, что свидетельствует о новизне этого понятия в педагогике и актуальности изучения данного вопроса.

Руководствуясь принципами компетентностного и деятельностного подходов в обучении иностранным языкам в высшей школе, наиболее целесообразно использовать следующую классификацию цифровых технологий:

1. Простейшие технологии, включающие традиционные методы обучения и электронные учебные пособия.

2. Технологии с применением электронных средств обучения при многоуровневом образовании и учитывающие гибкость при выборе метода.

3. Технологии дистанционного обучения (с использованием вебинаров, онлайн-курсов, проведение занятий в Zoom, Skype и других платформах), активизирующие коммуникативные методы работы в группе и способствующие развитию профессиональных компетенций у обучающихся.

4. Технологии сетевого и облачного взаимодействия - самые современные на данный момент цифровые технологии, включающие комплекс групповых активных методов и предполагающие владение информационной компетентностью и со стороны преподавателей, и со стороны обучающихся, доступность всех необходимых технических средств и ресурсов. В результате применения данного вида технологий формируются необходимые компетенции - языковая, речевая, коммуникативная, социокультурная и другие, играющие ключевую роль в становлении профессиональной компетентности обучающихся [9, с. 39-40].

Цифровые технологии сетевого и облачного взаимодействия используются как в групповой работе преподавателя и студентов в аудиториях и дистанционно, так и в индивидуальной работе, направленной на самостоятельное овладение определенными умениями и навыками (чтения, говорения, аудирования, письма на иностранном языке). Такая работа способствует саморазвитию личности обучающегося.

В настоящее время существует большое разнообразие электронных или цифровых ресурсов, используемых в обучении иностранным языкам, то есть это та информация, которая содержится в форме данных, в виде разных программ, электронных изданий, веб-сайтов, мультимедийных приложений, и доступна пользователям через всемирную сеть - Интернет. К цифровым ресурсам можно отнести разные поисковые системы: Google (Books, Scholar), Yandex, YouTube; электронные словари; новостные агентства, телевидение и видео; подкасты; электронные библиотечные системы. В данной статье рассматриваются цифровые ресурсы, которые применяются в высшей школе при обучении лексике иностранного языка.

Формирование лексического навыка является одной из основных задач при обучении иностранным языкам, так как знание лексики лежит в основе освоения навыков говорения, чтения, письма, аудирования, в результате чего у студентов появляется коммуникативная компетенция, необходимая для профессиональной деятельности. Так, в «Рабочей программе дисциплины “Иностранный язык” согласно учебному плану подготовки специалистов по специальности «Подвижной состав железных дорог» в качестве основной компетенции определена универсальная компетенция УК-4, которая предполагает формирование у обучающегося определенных умений и навыков: «УК-4.1 - Использует фонетические, графические, лексические, грамматические и стилистические ресурсы иностранного языка для обеспечения академического взаимодействия в устной и письменной речи», «УК-4.2 - Владеет профессиональной лексикой и базовой грамматикой для обеспечения профессионального взаимодействия в устной и письменной формах» [5]. Исходя из формулировки компетенции, представленной в рабочей программе изучаемой дисциплины, овладение лексикой иностранного языка для академического и профессионального взаимодействия студента в устном и письменном виде является одной из основных задач обучения иностранным языкам в высшей школе. Этим объясняется тот факт, что преподаватели стараются найти наиболее эффективные методы работы, способствующие лучшему усвоению иноязычной лексики, в том числе с использованием цифровых технологий, которые повышают интерес к изучению иностранных языков. 
На начальном этапе формирования лексического навыка, прежде всего, при ознакомлении студентов со специальной лексикой - лексикой определённой профессии, всегда доступны и удобны в использовании такие электронные словари, как Oxford Languages, Cambridge Dictionary, Collins Online Dictionary, Encyclopedia.com. Так, студенты при изучении темы “History of Railway Transport in Russia” («История железнодорожного транспорта в России») сталкиваются с рядом терминов, необходимых для восприятия и осмысления. С использованием электронных словарей обучающимся проще усваивать произношение лексемы (помимо транскрипции, в словаре есть возможность прослушивания), ознакомиться с написанием, грамматическими формами и структурными особенностями лексической единицы, а также с ее значением и определением. Семантизация лексем происходит как переводным (с помощью введения эквивалента на родном языке), так и беспереводным способом (в результате определения на иностранном языке или использования лексемы в контексте).

Например, онлайн словарь Oxford Learner’s Dictionary представляет полную информацию об английской лексеме “railway” («железная дорога»): часть речи (существительное), озвученное произношение, варианты перевода («железнодорожная линия»), толкование всех значений многозначного слова (1. “A track with rails on which trains run” / «путь с рельсами, по которому идут поезда»; 2. “A system of tracks, together with the trains that run on them, and the organization and people needed to operate them” / «система путей, поезда, которые по ним ходят, организация и люди, необходимые для их эксплуатации») [12] и примеры его использования в предложениях.

В словарной статье даются ссылки на другой электронный ресурс Oxford Collocations Dictionary, словарь устойчивых выражений английского языка, где дан список прилагательных, глаголов, существительных, предлогов, которые сочетаются с данной лексемой - railway (“mainline” / «магистраль», "high-speed” / «высокоскоростная», “disused” / «заброшенная» и т.п.). Студенты могут попрактиковаться на следующем этапе освоения лексического навыка - в закреплении новой лексики при выполнении разного рода упражнений, например:

- найдите иноязычную лексему в электронном словаре, ее перевод и толкование, изучите варианты сочетаемости данного слова;

- подберите синонимы, антонимы, производные слова и т.п.;

- составьте предложения с новой лексемой и с данными в словаре словосочетаниями на иностранном языке.

Кроме этого, в Oxford Learner’s Dictionary в словарной статье, посвященной лексеме “railway”, дан текст об истории первой в мире железной дороги в Англии на английском языке. Здесь же можно найти ссылки на сходные по тематике тексты «Бирманская железная дорога», «Железная дорога Ливерпуля и Манчестера». Студентам можно дать задание:

- прочитайте и переведите текст об истории первой в мире железной дороги, выпишите незнакомые слова и найдите в электронном словаре их эквиваленты на русском языке;

- предоставьте информацию на иностранном языке о старейшей железной дороге в Англии с использованием изученной лексики и т.п.

При чтении текстов на иностранном языке, их переводе и составлении монологических высказываний реализуется третий этап работы над формированием лексического навыка - применение лексического материала в письменной или устной речи на иностранном языке. В результате чего можно говорить о формировании коммуникативной компетенции у обучающихся иностранному языку в вузе.

Статьи на любые интересующие темы можно найти также в универсальной британской энциклопедии «Британника» (Britannica). Этимологический словарь (Online Etymology Dictionary) отличается от остальных электронных словарей тем, что помогает проследить историю определенного термина в английском языке, дает историческую справку, что необходимо при изучении специальной лексики любого профиля подготовки. Использование электронных словарей подразумевает формирование и активизацию отдельных мыслительных операций, памяти и восприятия.

Сервис Ngram Viewer от Google позволяет студентам подробно изучить термины в любой области науки на иностранном языке. В последнее время данный сервис стал весьма популярным, так как обладает рядом преимуществ: может подсчитать частоту употребления слов в книгах на протяжении последних веков; связан с книгами на разных языках мира; анализирует несколько десятков миллионов книг; представляет динамику употребления слов в виде графиков; дает ссылки на каждый результат поиска в Google Books; cpaвнивает динамику употребления нескольких слов; дает полный набор «сырых» данных исследования; делает анализ книг бесплатно. Таким образом, реализуется словесно-графический метод обучения с использованием приемов построения графиков, выявлением сравнительных и обобщающих характеристик изучаемых понятий, составлением лингвистических карт и кластеров.

Так, во время изучения истории железнодорожного транспорта в России на английском языке (“History of Railway Transport in Russia”) студенты выполняют задание по освоению новых терминов с использованием Google Ngram Viewer:

- составьте список ключевых слов, который может состоять как из терминов, так и имен собственных: например, “freight transportation” / «грузовые перевозки», “carrying сарасity” / «грузоподъемность», “platform wagons” / «вагоны-платформы», “tank wagons” / «вагоны-цистерны», “Trans-Siberian Railway” / «Транссибирская железнодорожная магистраль», “Cherepanovs” / «Черепановы», “Р. Р. Melnikov” / «П. П. Мельников» и другие лексемы;

- создайте лингвистическую карту или кластер на иностранном языке, куда входит ключевое слово, выделены основные смысловые единицы, представленные схематично, и обозначены все связи между ними; 
- продемонстрируйте все полученные данные в виде графика с использованием Google Ngram Viewer и проследите динамику употребления лексем на иностранном языке в разных источниках, сравните полученные результаты исследования и подготовьте сообщение о них на изучаемом языке.

Согласно Google Ngram Viewer, наибольшее количество книг можно найти о П. П. Мельникове. График показывает повышенный интерес к его фигуре на протяжении 220 лет (1800-2019 гг.). В 1850-е гг. он был автором проекта железной дороги Санкт-Петербург - Москва. 1872 г. - член Гос. Совета. Дальнейшее развитие идей Мельникова связано с ростом отечественных металлургических предприятий и железнодорожной отрасли, этим объясняются остальные пики популярности его идей (1970 г.). Из остальных терминов (грузопоток, грузоподъемность, вагоны-платформы, вагоны-цистерны) наибольшей популярностью пользуются термины - «грузоподъемность» и «грузопоток», что доказывает актуальность этих понятий на протяжении истории развития железных дорог. Проделанная работа носит характер проектной деятельности, способствует запоминанию нового лексического материала и формированию языковой, коммуникативной и в целом лингвистической компетенций студентов как одной из главных задач обучения иностранным языкам.

Дополнением к работе над новым лексическим материалом может послужить сервис Talk to Books (дословно «Поговори с книгами»), который также предоставляет список литературы по изучаемой теме, что необходимо для самостоятельной работы студентов. Talk to Books способствует и процессу закрепления новой лексики, и ее применению в иностранной речи. Преподаватель может попросить студентов воспользоваться сервисом Talk to Books как инструментом для творчества:

- составьте список книг на иностранном языке по изучаемой теме;

- исследуйте и проанализируйте идеи и цитаты авторов;

- предоставьте дополнительный материал на иностранном языке;

- обсудите на изучаемом языке актуальность темы в группах.

Talk to Books можно использовать: при подготовке к лекциям, семинарам; при организации самостоятельной работы студентов во время подготовки к семинарам; в групповой дискуссии обучающихся; при организации проектной и исследовательской деятельности студентов; при подборке тематических цитат, подборе различных точек зрения по изучаемой теме, для нахождения интересных книг.

Применение цифровых ресурсов при обучении иностранным языкам в вузе направлено на формирование лексических навыков, развитие коммуникативной компетенции у обучающихся и их способности к научноисследовательской деятельности.

\section{Заключение}

В результате исследования было дано научно обоснованное определение понятию «цифровые технологии» при обучении иностранным языкам, учитывающее компетентностный подход, лежащий в основе образовательного процесса в высшей школе. Кроме того, были установлены основные функции цифровых технологий в образовательном процессе: обучающая, воспитывающая, развивающая, мотивирующая и познавательная, которые свидетельствуют о том, что цифровые технологии сосредоточены на реализации традиционных задач педагогики. В ходе исследования была дана классификация видов информационно-коммуникационных технологий, описаны цифровые средства, используемые при обучении лексике иностранного языка.

Среди электронных ресурсов, применяемых при формировании лексических навыков в процессе преподавания иностранных языков в вузе, были проанализированы электронные словари, сервисы Google Ngram Viewer и Talk to Books. Они дают полную информацию о лексической единице на иностранном языке, позволяют обучающимся не просто запомнить ее значение, перевод, разобраться с сочетаемостью лексемы, ее парадигматическими отношениями, но и предоставляют возможность студентам провести исследование, посвященное этимологии слова, истории употребления или заняться изучением связанных тем и даже книг на языке. Так, в процессе обучения иностранным языкам в высшей школе развиваются лексические навыки, необходимые будущим выпускникам для профессионального взаимодействия в устной и письменной речи.

В результате использования цифровых технологий у обучающихся формируются необходимые компетенции (языковые, речевые, социолингвистические, коммуникативные и другие) в области иностранного языка. Цифровые технологии направлены также на развитие важных навыков самостоятельной работы и научноисследовательской деятельности, что способствует приобретению в результате обучения профессиональной компетентности студента.

Перспективы дальнейшего исследования заключаются в изучении вопроса отражения цифровых технологий в официальных документах, что позволит использовать цифровые ресурсы в полном объеме на занятиях по иностранным языкам с целью повышения качества образования.

\section{Список источников}

1. Артюшина Л. А., Спирина Т. В., Троицкая Е. А. Компьютерные технологии в науке и образовании: учеб.практ. пособие. Владимир: Изд-во ВлГУ, 2018. 228 с.

2. Гальперин П. Я. Основные результаты исследований по проблеме «Формирование умственных действий и понятий»: автореф. дисс. .... д. пед. н. М., 1965. 49 с. 
3. Исаева Т. Е. Использование информационно-коммуникационных технологий в процессе обучения иностранным языкам в вузе: методологический аспект // Общество: социология, психология, педагогика. 2020. № 3. C. 111-117.

4. Кащук С. М. Теоретико-прагматические основы модели формирования учителя французского языка с использованием мультимедиатехнологий: монография. М.: КДУ, 2011. 228 с.

5. Маруневич О. В., Котляренко Ю. Ю., Одарюк И. В. Рабочая программа дисциплины 1 Б.О «Иностранный язык» по Учебному плану подготовки специалистов по специальности 23.05 .03 «Подвижной состав железных дорог» [Электронный ресурс]. Ростов-на-Дону: ФГБОУ ВО «РГУПС», 2020. URL: https://portal.rgups.ru/ upload/educontent/rpd/167127.html (дата обращения: 19.02.2021).

6. Полат Е. С. Современные педагогические и информационные технологии в системе образования. М.: Академия, 2007. 368 с.

7. Польщиков А. В. Понятие информационно-коммуникационных технологий в системе технико-криминалистического обеспечения деятельности ОВД // Российский следователь. 2010. № 16. С. 33-35.

8. Роберт И. В. Современные информационные технологии в образовании: дидактические проблемы, перспективы использования: монография. М.: ИИО РАО, 2010. 140 с.

9. Современные цифровые и информационно-коммуникационные технологии формирования универсальных компетенций обучающихся университета в процессе преподавания иностранных языков: колл. монография / под ред. Т. Е. Исаевой. Ростов-на-Дону: ФГБОУ ВО «РГУПС», 2020. 232 с.

10. Троицкая Е. А. Информационные технологии в учебном процессе: учебное пособие. Владимир: Изд-во ВлГУ, 2020. $166 \mathrm{c}$.

11. Ямалетдинова А. М., Медведева А. С. Современные информационные и коммуникационные технологии в учебном процессе // Вестник Башкирского университета. Серия «Педагогика и психология». 2016. Т. 21. № 4. C. 1134-1141.

12. Oxford Learner’s Dictionaries [Электронный ресурс]. URL: https://www.oxfordlearnersdictionaries.com/ (дата обращения: 19.02.2021).

\section{Информация об авторах | Author information}

RU Колесниченко Альвина Николаевна ${ }^{1}$, к. филол. н., доц.

${ }^{1}$ Ростовский государственный университет путей сообщения

EN Kolesnichenko Alvina Nikolaevna ${ }^{1}, \mathrm{PhD}$

${ }^{1}$ Rostov State Transport University

${ }^{1}$ kolesnichenkoa@mail.ru

Информация о статье | About this article

Дата поступления рукописи (received): 06.02.2021; опубликовано (published): 30.04.2021.

Ключевые слова (keywords): цифровые технологии в обучении лексике; иностранный язык; высшая школа; формирование компетенций; digital technologies in teaching vocabulary; foreign language; higher school; competences formation. 